Journal of Education and Vocational Research

Vol. 5, No. 3, pp. 125-137, September 2014 (ISSN 2221-2590)

\title{
Causes of Conflict in Organizations: A Case of Takoradi Polytechnic
}

\author{
Sarah Morrison*, Jeffrey Mingle, Samuel Sundong \\ Accra Polytechnic, Department of Quality Assurance, Ghana \\ smorrison@apoly.edu.gh*
}

\begin{abstract}
The study explored the various causes of conflicts in organizations. The objectives of the study was to find out the nature, types and factors that lead to staff related conflicts in organizations especially tertiary educational institutions. To achieve the objectives, researchers employed the case study approach using Takoradi Polytechnic as the case study. It also involved the use of interview and questionnaire as the data collection instruments for the study. Researchers used the purposive and simple random sampling techniques to select the respondents. A sample size of 276 out of 736 of the population was selected for the study. This constitutes (36\%) of the population. The sample was made up of 109 junior staff, 96 senior staff and 71 senior members. These three groups of staff from different departments were randomly and purposively invited to participate in the study. The study would be of immense benefit to management of institutions especially educational institutions since it would inform them of possible conflict that could arise. It would also inform policy formulation and staff training and development programs. It was discovered after the study that there were various conflicts in the organization which could be grouped into intra-personal, interpersonal and inter-group conflicts. These were as a result of the competing for limited resources, power struggle, differences in behavior among others. It recommends the education of staff through workshops and seminars on the differences that leads to conflicts, provision of resources and infrastructure that could mitigate the competition of resources among others.
\end{abstract}

Keywords: Conflicts, Takoradi, Polytechnic, Staff, Causes

\section{Introduction}

Conflict appears to be a universal characteristic of human associations. It is difficult to imagine either simple or complex relationships which are not in part defined by the nature of the conflicts which test and vitalize the bonds people form with each other. At the same time, it is difficult to accept conflict as a natural and inevitable condition. It is an uncomfortable condition; one for which the natural tendency is to seek a resolution. Conflict is generally regarded as disagreement regarding interest or ideas (Esquivel \& Kleiner, 1997). Bagshow (1998) notes that conflict is a fact of life in organizations as well as other areas of life, as people compete for jobs, resources, power, acknowledgement and security. French (2000), Barker, Tjosuold and Andrews (1998) and Dahrendorf (1989), in separate studies, commonly discovered four conditions which are vital for a conflict situation to exist. These conditions are:

- There must be sets of individuals exhibiting some levels of togetherness in an organization. These could be voluntary groups, religious groups, families, communities, nations, or some other collections of individuals.

- There must be some level of interaction among members because without contact and communication there can be no conflict. The contact may merely be propaganda about other people, culture, or group since it need not be personal.

- There must be different levels of positron or status ranks to be occupied by group members, implying a hierarchy of relationships. All individuals cannot occupy the same position at the same time.

- There must be existence of scarcity of needed resources and a general dissatisfaction.

It could also be said that the probability of conflict occurring is higher when there is a larger group of people than when the group is small. This is so because diversity among members of a group results in difference in goal, beliefs, perceptions, and preferences. Conflict occurs on the basis of the fact that human wants are insatiable but our resources to satisfy these wants are limited or relatively scarce hence the conflict. Again, in Ghanaian tertiary educational institutions, there are workers with different qualifications which could bring 
about personality conflicts. This may involve people with low academic qualifications who have stayed on the job for a longer period of time, as against those with high qualifications, but have been on the job for a relatively short period. Thus it should not be a surprise that an institution such as Takoradi Polytechnic could be a fertile ground for conflict since it has a great number of people with diverse views and aspirations. Conflicts provide feedback to management because it tends to bring issues to the fore. When under stress, people are more likely to express their real feelings which otherwise may not have surfaced for redress. At the workplace, conflict can be a source of testing management ability to demonstrate effectiveness in handling welfare issues of subordinate. It tests the power of management by their subordinates to see if management acts on their behalf. It also tests the will power of individuals and the staying power of employees. The predominant outcome of conflict is change. Change is a process of education and it plays a major role in the development of tertiary education. The educational mission of higher educational institutions requires the ability to maintain flexibility to adapt to societal needs and to lead in the advancement of knowledge and social transformation. When conflict among staff of such institutions is viewed as a catalyst for learning and change, it can lead to the advancement of knowledge and societal transformation. As social system, Takoradi Polytechnic has social structures, these structures; whether they exist formally or informally are the blue print for control and hierarchies. It is within these hierarchies that conflict is triggered. To what extent has management of Takoradi Polytechnic been able to identify these conflicts and used it to the advantage of the institution and the employees?

\section{Objectives}

- To find out the nature of staff related conflicts in organizations

- To ascertain the various types of conflicts that arise in organizations

- To discover the factors that lead to staff related conflicts in organizations

\section{Literature Review}

Definition of Conflict: Hellriegel Slocum \& Woodman (1998) argue that the term conflict is difficult to define, because it occurs in many different settings. They further explain that the fundamental nature of conflict seems to be disagreement, contradiction or incompatibility and thus, refers to any situation in which there are incompatible goals, cognitions or emotions within or between individuals or groups that lead to opposition or aggressive interaction. An activity that is incompatible with another is one that prevents, blocks or interferes with the occurrence of the second activity. Certo (2000) buttresses this statement by defining conflict as the struggles that result from incompatible or opposing needs, feelings thoughts or demands within a person or between two or more people. In an apparent support of this view, Nelson and Quick (2000) define conflict as any situation in which incompatible goals, attitudes, emotions or behaviors lead to disagreement or opposition between two or more parties. Tjosvold, cited in Kreitner (1998), gives an insightful definition, according to him, conflict involves incompatible behaviors; one person interfering, disrupting or in some other way making another's action less effective. Thus, conflict can be compared to a situation that makes one feel less effective. Based on the above definitions, Kreitner (1998) came out with two faces of conflict, namely competitive (or destructive) conflict and cooperative (or constructive) conflict.

Causes of Conflicts in Organizations: To manage conflict effectively, managers must identify and understand the many causes of conflicts in organizations. Working teams bring together a variety of personality and skills, each perceiving tasks and actions in different ways. This diversity is what gives the team in-depth and broad range of skills required to successfully achieve organizational objectives; yet, this diversity will usually, inevitably bring conflicts ranging from simple disagreements on task to fundamental personality clashes. Causes of conflict could be classified into two broad categories: Structural factors, which stem from the nature of the organization and the way in which work is organized and personal factors, which arise from differences among individuals (Nelson \& Quick (2000), Mcshane \& Glinow (2000), Schnake (1987) and Krietner \& Kinicki (2004). They explain further that some causes of conflict that relate to the organization's structure include specialization, interdependence, common resources, goal differences, authority relationship, status, inconsistencies, and jurisdictional ambiguities. With regard to causes of conflict relating to personal factors, they intimate that it springs from individual differences which include skills and abilities, personalities, perceptions, values and ethics, emotions, communication barriers and cultural differences. Schnake (1987) defines interdependence as situations where one party cannot do its work unless the other 
party does its work too. According to him, task interdependence results in conflict for two main reasons. The first is when only one group is dependent; the independent group may not feel the need to comply with requests.

Pooled interdependence, according to Wright and Noe (1996), is a situation where each group works separately but the organization's overall success rests on the total performance of the groups, while they assert that sequential interdependence requires one group's output to serve as another group's inputs. Schnake (1987) observes that the differences in the goals that individuals or groups want to accomplish could create a source of conflict. He explains that when individuals have incompatible personal goals, conflict is likely to occur. This assertion is buttressed by Pondy's, (1969) observation that when two parties in an organization must work together, for example, a dean of faculty and the head of department of the same faculty may have divergent views on how certain courses are to be conducted and may not agree on how to do so. This source of conflict is goal divergence. Krietner and Kinicki (2004) also see organizational complexity as a major cause of conflict in most organizations. They explain this as where conflict is triggered as a result of the number of hierarchical layers and specialized task increase. According to Nelson and Quick (2000), specialization is one of the structural factors that cause conflict in an organization. When jobs are highly specialized, employees become experts at a particular task. This makes them less knowledgeable about other people's job leading to conflict situation. Kinard (1998), point out that too much of specification can cause conflict among employees. Stoner (1978) indicates that limited resources in an organization could be a potential cause of conflict. He explains that since every unit in an organization has limited access to human and material resources, the problem of how to share these resources could trigger conflict. This is confirmed by Nelson and Quick (2000) in their observation that any time multiple parties must share resources, there is potential for conflict.

Personal Factors: Oppong-Mensah (1999) contends that since organizations and institutions have greater numbers of people, it tends to be fertile grounds where conflicts of many kinds are initiated and felt. According to Nelson and Quick (2000), the causes of conflict that arise from individual differences include skills and abilities, personalities, perceptions, values and ethics, emotions, communication barriers and cultural differences. Under the skills and abilities, they explained that the work force of any organization is composed of people with varying levels of skills and abilities which help the organization to achieve its goal. These skills and abilities of the workforce also hold potential for conflict, especially when jobs are interdependent. A competent worker may feel uncomfortable to work with less competent workers. Besides, other workers may feel their skills are more important and needed by the organization than other workers' skills and abilities. With regard to personalities, Nelson and Quick (2000) contend that people come to work places with diverse character traits which may negatively affect their relationships leading to conflict. For instance, to expect to like all your co-workers may be a naïve expectation, as would be the expectation that they will all like you. On perception, they explain that because people perceive things differently, it could serve as a cause of conflict in an organization. An example is in the area of motivation. If management and workers do not have the same perception of what motivates people, the reward system can create conflicts. Since management usually provides what they think employees want rather than what employees really need. Nelson and Quick (2000) point out that most people have their own sets of values and ethics but the extent to which they apply these ethics in the work place varies. Some people have strong desires for approval from others and will work to meet such people's ethical standards: others are relatively unconcerned with approval from others and strongly apply their own ethical standards; still others operate seemingly without regard to ethics or values. They also assert that the moods of others can be a cause of conflict in the workplace. Problems at home often spill over into the work arena and the related mood can be hard for others to deal with. Mullins (2005) also sees changes in an organization as a cause of conflict. He is of the view that rapid and repeated internal changes can be a source of worry. He explains further that changes bring about disequilibrium. Some people may be favored when there is change in the organization and therefore will welcome it; others may be at a disadvantage and feel insecure with the inability to predict patterns with regard to the known. Such people will inevitably find ways to resist and defeat changes they perceive as threatening to their well being or to their social role.

Levels of Conflict: This section deals with the nature and organizational implication of four basic types of conflict. These are: interpersonal conflict, intrapersonal conflict, intergroup conflict and organizational 
conflict. Inter-personal conflict occurs between two or more people. It normally arises as a result of two or more people competing for the same job, position or for limited resources (Rao, Rao, \& Narayana, 1987). According to Mcshane and Glinow (2000), the most commonly cited reasons for inter-personal conflict in organizations are personality differences, perceptions, clashes of values and interests, power and status differences, and scarce resources. According to Nelson and Quick (2000), there are several types of intrapersonal conflict, some of which are: inter-role, intra-role and person-role conflicts. They define role as a set of expectation placed on an individual by others. The person occupying the focal role is the role incumbent and the individuals who place expectations on the person are role senders. On the various types of intrapersonal conflict, they explain inter-role conflict as one that occurs when a person experiences conflict among multiple roles in his or her life. It often arises when a person receives conflicting messages from role senders as to how to perform a certain role. Suppose a Rector receives counsel from his personnel manager that he needs to socialize less with management employees, whilst he has also been told that in order to be a good leader he must relate well with all his personnel, this may result in intra-role conflict. Inter-group conflict is the most frequent occurring problem facing managers in large organizations. According to Likert \& Likert (1976), inter-group conflict occurs between groups or teams in an organization. They explain further that it arises as a result of the following situations: groups fighting for scarce resources, differences of opinion about the way a unit should be managed, dependence of one group on another, communication problems, and different interest and goals as well as lack of clarity of responsibilities. Wright and Noe (1996), note that inter-group conflict in organizations often arises between line and staff employees. The line employees are those who are directly involved in organization's product whilst staff employees provide supportive services.

\section{Methodology}

The study chose the case study method approach. Takoradi Polytechnic was chosen as the case study organization because it is one of the oldest polytechnics in the country. A sample size of 276 out of 736 of the population was selected for the study. The study used questionnaire and interview as the data collection instruments.

\section{Results and Discussion}

Table 1: Gender

\begin{tabular}{llll}
\hline Gender & Frequency & Percentage & (\%) \\
\hline Male & 174 & 66.4 & \\
Female & 88 & 33.6 & \\
Total & 262 & 100 & \\
\hline
\end{tabular}

Table 1 depicts that $174(66.4 \%)$ of the respondents were males as against 88 (33.6\%) females. This situation is not peculiar as is usually the case in many organizations due to the fact that there is a gender imbalance in the various positions in many organizations and in the country as whole. The views of males were therefore dominant in the study.

Table 2: Staff Category

\begin{tabular}{lll}
\hline Staff Category & Frequency & Percentage (\%) \\
\hline Teaching & 52 & 19.8 \\
Non-Teaching & 210 & 80.2 \\
Total & 262 & 100 \\
\hline
\end{tabular}

It can be observed from Table 2, that majority 210 (80.2\%) of the respondents belong to the non-teaching category of staff when compared with that of the teaching staff category of $52(19.8 \%)$ respondents. This could be attributed to the fact that the majority of the staff at the Polytechnic fall under middle level manpower group with a few senior members in the teaching category and at the top administrative positions such as the rector, vice rector and the registrars. It is surprising that about $86(33 \%)$ of the respondents for unknown reasons did not indicate their academic qualification. However, it is gratifying to note from Table 3, that majority $59(22.5 \%)$ of those who provided responses were holders of first degree followed closely by those 52 (19.8\%) holding second degree. In the Polytechnic set up, senior members require higher degrees. 
They form the academic and top administrative staff members such as the Rector, Vice Rector and Registrars. Senior staff should hold at least first degree and the junior staff should at least have SSSCE.

Table 3: Highest Educational Qualification of Staff

\begin{tabular}{lll}
\hline Level & Frequency & Percentage (\%) \\
\hline SSCE & 11 & 4.2 \\
No Response & 86 & 32.8 \\
Specialist & 19 & 7.3 \\
HND & 35 & 13.4 \\
Degree & 59 & 22.5 \\
Postgraduate & 52 & 19.8 \\
Total & 262 & 100 \\
\hline
\end{tabular}

Nature and causes of conflicts among Staff of Takoradi Polytechnic: Objective one and two sought to explore the nature of conflicts in Takoradi Polytechnic and causes of such conflicts. The data suggests that the three types of conflicts: intrapersonal, interpersonal and intergroup conflicts characterize the nature of conflicts in the polytechnic. The intrapersonal and interpersonal conflicts included five and seven possible factors respectively, while the inter-group conflicts covered seven issues which are thought to result in conflicts between junior staff and senior staff, junior staff and senior members and senior staff and senior members in that order. Therefore each broad area is examined in the light of the issues involved

Cause of Intrapersonal Conflicts: With regard to the causes of intrapersonal conflicts, five factors identified as causes of intrapersonal conflict in the literature review were included in the survey questionnaire. Respondents were asked to indicate which of the five factors can be identified as causes of intrapersonal conflict. Respondents were to indicate one or more of these factors. Table 4 shows the multiple responses reported by the respondents

Table 4: Causes of Intra personal conflicts among staff of Takoradi polytechnic

\begin{tabular}{|c|c|c|c|c|c|c|c|c|}
\hline \multirow[t]{2}{*}{ Causes } & \multicolumn{2}{|c|}{ Senior Member } & \multicolumn{2}{|c|}{ Senior Staff } & \multicolumn{2}{|c|}{ Junior Staff } & \multicolumn{2}{|c|}{ Total } \\
\hline & $\mathbf{N}$ & $\%$ & $\mathbf{N}$ & $\%$ & $\mathbf{N}$ & $\%$ & & $\%$ \\
\hline $\begin{array}{l}\text { Choosing between equality good } \\
\text { initiatives }\end{array}$ & 28 & 20.6 & 36 & 17 & 22 & 12.5 & 86 & 16.4 \\
\hline $\begin{array}{l}\text { Choosing between equally bad } \\
\text { alternatives }\end{array}$ & 8 & 5.9 & 44 & 20.8 & 22 & 12.5 & 74 & 14.1 \\
\hline Choosing among a set of options & 32 & 23.5 & 44 & 20.8 & 66 & 37.5 & 142 & 27.1 \\
\hline $\begin{array}{l}\text { When not quite clear about role } \\
\text { as a staff }\end{array}$ & 40 & 29.4 & 44 & 20.8 & 22 & 12.5 & 106 & 20.2 \\
\hline Different expectations about job & 28 & 20.6 & 44 & 20.8 & 44 & 25 & 116 & 22.2 \\
\hline
\end{tabular}

Table 4, reveals that a total of 524 responses were reported, and of these, the highest number of 212 was reported by the senior staff while the least number of 136 were reported by the senior members. "Choosing from among a set of options that has good and bad outcomes" was the most frequent mentioned cause of intrapersonal conflict among the junior staff. Among the senior members, "When not quite clear about role as a staff" was identified as the leading cause of intrapersonal conflicts"? Form the senior staff, four options were equally cited as the leading causes of intrapersonal conflicts namely; 'choosing between two equally bad alternatives', 'choosing among a set of options that have good or bad outcomes', 'when not quite clear about role as a staff' and 'when you have different expectations about your job'. The least reported cause of intrapersonal conflict among the three categories of respondents was "Choosing between equally good alternatives" with the least mention of this cause from the junior staff, followed by the senior members and senior staff respectively. This finding is in agreement with Wright and Noe's (1996) identification of type of intrapersonal conflict. These are "Approach-Approach" which deals with choosing between two equally attractive, profitable and desirable alternatives; "Avoidance-Avoidance" where the individual is also torn between choosing two equally bad, undesirable and unattractive alternatives that have bad consequences and "Approach-Avoidance" which deals with choice among a set of options that have both good and bad outcomes. Respondents were asked to select from eight possible factors they thought were the causes of 
interpersonal conflicts in their Polytechnic. Respondents were to tick as many as possible. The responses are presented in Table 5.

Table 5: Causes of Interpersonal Conflicts among Staff in Takoradi Polytechnic

\begin{tabular}{|c|c|c|c|c|c|c|c|c|}
\hline \multirow[t]{2}{*}{ Causes } & \multicolumn{2}{|c|}{ Senior Member } & \multicolumn{2}{|c|}{ Senior Staff } & \multicolumn{2}{|c|}{ Junior Staff } & \multicolumn{2}{|c|}{ Total } \\
\hline & $\mathbf{N}$ & $\%$ & $\mathbf{N}$ & $\%$ & $\mathbf{N}$ & $\%$ & & $\%$ \\
\hline Differences in Behavior & 40 & 17.5 & 76 & 20.9 & 77 & 22.6 & 193 & 20.7 \\
\hline Among Individual Staff & & & & & & & & \\
\hline $\begin{array}{l}\text { Relationship between } \\
\text { Superior and Subordinate }\end{array}$ & 28 & 12.3 & 40 & 11.0 & 44 & 12.9 & 112 & 12.0 \\
\hline Struggling for position & 40 & 17.5 & 56 & 15.4 & 55 & 16.1 & 151 & 16.2 \\
\hline $\begin{array}{l}\text { Competing for limited } \\
\text { resources }\end{array}$ & 44 & 19.3 & 40 & 11.0 & 11 & 3.2 & 95 & 10.2 \\
\hline Gossiping & 16 & 7.0 & 48 & 13.2 & 66 & 19.4 & 130 & 13.9 \\
\hline Differences in perception & 32 & 14.0 & 64 & 17.6 & 55 & 16.1 & 151 & 16.2 \\
\hline Feeling of superiority & 28 & 12.3 & 40 & 11.0 & 11 & 3.2 & 79 & 8.5 \\
\hline Lack of respect & 0 & 0 & 0 & 0 & 22 & 6.5 & 22 & 2.4 \\
\hline Total & 228 & 100.0 & 364 & 100.0 & 341 & 100.0 & 933 & 100.0 \\
\hline
\end{tabular}

From Table 5, among the senior members competing for limited resources and recognition 44 (19.3\%) was mentioned as the leading factor that causes interpersonal conflict. From the senior and junior staff side, differences in behavior, among individual staff was reported as the leading cause with $76(20.9 \%)$ and 77 $(22.6 \%)$ respectively. Overall, however, this study has revealed that the respondents are aware of the factors promoting interpersonal conflicts among the staff of the polytechnics with more frequent mention of "Differences in behavior among individual staff", "Power struggle", and Differences in perception" as the top three factors promoting interpersonal conflicts among the staff of the polytechnics. The interview sessions with selected senior members of the Polytechnic on the cause of interpersonal conflict confirmed the findings of the survey questionnaire. Commonly emerging from the results of interview data were views that indicated that, most of the time, "gossip" and "envy" are most prevalent causes of conflicts in the polytechnic. One Dean, for example, remarked: 'My sister, I bet you ... conflict involving staff that take most of my time are often related to accusations of gossiping about someone or the other ...' they also mentioned factors such as mode of awarding scholarship for further studies, claim of superiority, struggle for positions, limited resources and emotions. Others include; jealousy among workers and lack of trust. A female registrar lamented about the selective nature of awarding study leave with pay in the polytechnic stressing that such discriminative acts generate unnecessary tension and hatred among staff leading to conflicts: 'Hmm, it's a pity but I,ve got to mention it ... there is no fairness in the polytechnic. Who you know is what makes study leave applications easy. If you don't know any big man ... you better keep quiet and stay as a common worker' (a female head). This finding is in agreement with what Nelson and Quick (2000) termed as personality conflict which relate to individuals perceptions, emotions, values and ethics, which they exhibit at work places.

Rao et el (1987) have also observe that the most commonly cited causes for interpersonal conflict are personality differences, clashes of values and interest, perceptions, power and status differences as well as scarce resources. Schnake (1987) also noted that interpersonal conflict may arise because of personality differences in basic beliefs and values or incompatible goals. Since Takoradi Polytechnic is made up of people from different background with different values, attitudes, norms and ideologies such differences are bound to register. However, the findings from the interview conducted revealed that fighting for positions, gossip and enviousness were the major causes of interpersonal conflict among the staff of the polytechnic. Another dimension of objective one was to identify the causes of intra-group conflicts, (i.e., Conflict between junior staff and senior staff on one hand and conflict between junior staff and senior members on the other hand, and senior staff and senior members). Respondents were asked to indicate the extent to which they thought issues such as limited resources, deficiencies in information flow, conflicting interest, overlapping tasks, interdependence, time pressure and collective decision-making results in conflict between junior staff and senior members, junior staff and senior staff, and senior staff and senior members. The results are presented in Table 6. 
Table 6: Causes of Inter-group Conflicts among the various Categories of Staff

\begin{tabular}{|c|c|c|c|c|c|c|c|c|c|c|c|}
\hline \multirow[t]{3}{*}{ Causes } & \multirow[t]{3}{*}{ Respondents } & \multicolumn{10}{|c|}{ Frequency/Percentage Responses } \\
\hline & & \multicolumn{2}{|c|}{$\begin{array}{l}\text { Very Large } \\
\text { Extent }\end{array}$} & \multicolumn{2}{|c|}{$\begin{array}{l}\text { Large } \\
\text { Extent }\end{array}$} & \multicolumn{2}{|c|}{$\begin{array}{l}\text { Little } \\
\text { Extent }\end{array}$} & \multicolumn{2}{|c|}{$\begin{array}{l}\text { Very Little } \\
\text { Extent }\end{array}$} & \multicolumn{2}{|c|}{ Total } \\
\hline & & $\mathbf{N}$ & $\%$ & $\mathbf{N}$ & $\%$ & $\mathbf{N}$ & $\%$ & $\mathbf{N}$ & $\%$ & $\mathbf{N}$ & $\%$ \\
\hline \multirow{4}{*}{ Limited resources } & SM & 0 & 0 & 12 & 21.4 & 32 & 57.1 & 12 & 21.4 & 56 & 100 \\
\hline & SS & 16 & 16.7 & 28 & 29.2 & 40 & 41.7 & 12 & 12.5 & 96 & 100 \\
\hline & JS & 77 & 70.0 & 0 & 0 & 0 & 0 & 33 & 30.0 & 110 & 100 \\
\hline & Total & 93 & 35.5 & 40 & 15.3 & 72 & 27.5 & 57 & 21.8 & 262 & 100 \\
\hline Deficiencies & SM & 8 & 14.2 & 24 & 42.9 & 12 & 21.4 & 12 & 21.4 & 56 & 100 \\
\hline \multirow[t]{3}{*}{ Information flow } & SS & 40 & 41.7 & 36 & 37.5 & 12 & 12.5 & 8 & 8.3 & 96 & 100 \\
\hline & JS & 22 & 20.0 & 44 & 40.0 & 0 & 0 & 44 & 40.0 & 110 & 100 \\
\hline & Total & 70 & 26.7 & 104 & 39.7 & 24 & 9.2 & 64 & 24.4 & 262 & 100 \\
\hline \multirow[t]{4}{*}{ Conflicting interest } & SM & 16 & 28.6 & 16 & 28.6 & 12 & 21.4 & 12 & 21.4 & 56 & 100 \\
\hline & SS & 28 & 29.2 & 52 & 54.2 & 12 & 12.5 & 4 & 4.2 & 96 & 100 \\
\hline & JS & 20 & 66.0 & 33 & 30.0 & 44 & 40.0 & 11 & 10.0 & 110 & 100 \\
\hline & Total & 66 & 25.2 & 101 & 38.5 & 68 & 6.0 & 27 & 10.3 & 262 & 100 \\
\hline \multirow[t]{5}{*}{ Overlapping Tasks } & SM & 8 & 14.3 & 4 & 7.1 & 24 & 42.9 & 20 & 35.7 & 56 & 100 \\
\hline & SS & 36 & 37.5 & 28 & 29.2 & 20 & 20.8 & 12 & 12.5 & 96 & 100 \\
\hline & JS & 55 & 50.0 & 11 & 10.0 & 11 & 10.0 & 33 & 30.0 & 110 & 100 \\
\hline & & 99 & 37.8 & 43 & 16.4 & 55 & 21.0 & 65 & 24.8 & 262 & \\
\hline & Total & & & & & & & & & & 100 \\
\hline \multirow[t]{4}{*}{ Interdependence } & SM & 20 & 35.7 & 8 & 14.3 & 20 & 35.7 & 8 & 14.3 & 56 & 100 \\
\hline & SS & 16 & 16.7 & 32 & 33.3 & 40 & 41.7 & 8 & 8.3 & 96 & 100 \\
\hline & JS & 33 & 30.0 & 22 & 20.0 & 11 & 10.0 & 44 & 40.0 & 110 & 100 \\
\hline & Total & 69 & 26.3 & 62 & 23.7 & 24 & 27.1 & 60 & 22.9 & 262 & 100 \\
\hline \multirow[t]{4}{*}{ Time Pressure } & SM & 0 & 0 & 16 & 28.6 & 71 & 42.9 & 16 & 28.6 & 56 & 100 \\
\hline & SS & 12 & 12.5 & 32 & 33.3 & 40 & 41.7 & 12 & 12.5 & 96 & 100 \\
\hline & JS & 66 & 60.0 & 11 & 10.0 & 11 & 10.0 & 22 & 20.0 & 110 & 100 \\
\hline & Total & 78 & 29.8 & 59 & 22.5 & 75 & 28.6 & 50 & 19.1 & 262 & 100 \\
\hline Collective & SM & 16 & 28.6 & 0 & 0 & 16 & 28.6 & 24 & 42.9 & 56 & 100 \\
\hline \multirow[t]{3}{*}{ Decision-making } & SS & 40 & 41.7 & 16 & 16.7 & 36 & 37.5 & 4 & 4.2 & 96 & 100 \\
\hline & JS & 55 & 50.0 & 33 & 30.0 & 0 & 0 & 22 & 20.0 & 110 & 100 \\
\hline & Total & 111 & 42.4 & 49 & 18.7 & 52 & 19.8 & 50 & 19.1 & 262 & 100 \\
\hline
\end{tabular}

Key: $\quad$ SM - Senior Members

SS - Senior Staff

JS - Junior Staff

Looking at table 6, data on limited resources reveal that a total of 262 individuals were investigated and of these 56 were senior members, 96 were senior staff and 110 were junior staff. Majority of the senior members totaling 32 (57.2\%) expressed the view that to a little extent limited resources is a contributing factor to inter-group conflict in their institution. None of the senior members associated themselves with the view that to a very large extent limited resources can lead to inter-group conflict in their institution. On the side of the senior staff, $40(41.7 \%)$ constituting the simple majority also expressed the same view that to a very little extent limited resources can lead to inter-group conflict in their institution. Interestingly, 77 (70\%) of the junior staff attest to the fact that to a very large extent limited resources is a contributing factor to inter-group conflict in their institution with only $33(30 \%)$ reporting that to a very little extent limited resources can lead to inter-group conflict in their institution. But all together, 57 (21.8\%) of the respondents reasoned that to a very little extent limited resources is an issue that can result in inter-group conflict especially conflict between junior staff and senior staff, and senior members and senior staff and above all among the senior members, senior staff and junior staff. This could be attributed to the fact that these groups use different resources in their activities. These findings suggest that though limited resources could lead to inter-group conflict as noted by Kinard (1998), it depends on whether the groups involved share common resource. In respect to deficiency in information flow, as can be seen from the table, there are more respondents who were of the view that deficiency in information flow to a large extent or to a very large extent promotes inter-group conflicts in comparison with those who were of the opinion that deficiency in information flow promotes inter-group conflicts but to a little or to a very little extent. 
In specific terms majority of 32 (57.1\%) of senior members investigated, expressed the view that to a large extent or to a very large extent, deficiency in information flow results in conflict between junior staff and senior staff. The story is not different from the side of both the senior and junior staff when majority in each case also expressed the same view. Indeed, a total of $76(79.2 \%)$ senior staff and a total of $66(60 \%)$ of the junior staff reported that truly to a large extent or to a very large extent deficiency in information flow results in conflict between junior staff and senior staff, junior staff and senior members and senior staff and senior members. In a nut shell, this study has revealed that majority of the respondents totaling $174(66.4 \%)$ think that the issue of deficiency in information flow to a large or to a very large extent is a source of inter-group conflict particularly between junior staff and senior staff, junior staff and senior members and senior staff and senior members. This finding substantiates the view of Schnake (1987), that when groups lack information about their activities in the same institution, misconception and distrust develop and this May likely lead to conflict. In terms of conflicting interest, it can be observed from the table that there was a split decision among the senior members on the extent to which the issue of conflicting interest results in inter-group conflicts in the institution. In particularly, $32(57.2 \%)$ of the senior members, reported that to a large extent or to a very large extent conflicting interest results in inter-group conflicts between junior staff and senior staff, junior staff and senior members, and senior staff and senior members whilst 24 (42.8\%) expressed the view that even though conflicting interest is a contributory factor, it does so to a little or to a very little extent. The story is not different from that of the senior staff as $80(83.4 \%)$ attest to the fact that to a large extent or to a very large extent conflicting interest results in inter-group conflicts between junior staff and senior staff, junior staff and senior members, and senior staff and senior members.

The simple minority of senior staff even though thought that conflicting interest is a contributory factor, it does so to a little or to a very little extent. On the part of the junior staff, the story was different, for instance $33(30.0 \%)$ reported that to a large extent conflicting interest contribute to inter-group conflict in their institution with only $11(10.0 \%)$ associating themselves to the fact that conflicting interest contribute to inter-group conflict to a very large extent. But in all, this study has again established that majority of respondents; totaling 167 (63.7\%), believe that conflict of interest indeed is a factor that can lead to conflicts between junior staff and senior staff, junior staff and senior members and senior staff and senior members. This finding confirms Likert and Likert (1976) and Pondy's (1969), claim that group with different interest and goals in the same institution lead to inter-group conflict. Schnake (1987) also observed that when groups have incompatible goals they turn to work toward achieving their own goals instead of overall organizational goal. When asked to indicate whether the issue of overlapping tasks results in inter-group conflicts, the majority of senior staff and junior staff totaling $64(66.7 \%)$ and $66(60 \%)$, respectively reported that they think that it results in inter-group conflict. This is to be compared with majority 44 (78.6) of senior members who think so but expressed the view that the issue of overlapping tasks results in inter-group conflict to a little or to a very little extent. However, the overall revelation from this study is that the majority of respondents admit that overlapping task results in inter-group conflict between junior staff and senior staff, junior staff and senior members and senior staff and senior members. This finding buttresses Mcshane and Glinow's (2000), explanation that overlapping task leads to role ambiguity which breeds conflict since employees may not be certain about their roles and may interfere with each other's role which could serve as a fertile ground for conflict. The next dimension of inter-group conflict that was investigated by this study was the issue of interdependence. Interestingly, data on it clearly shows that there is a split decision on this issue among senior members, senior staff and among junior staff.

For instance, a total of 28 (50\%), of the senior members agree that to a large extent or to a very large extent interdependence results in inter-group conflicts particularly between junior staff and senior staff, junior staff and senior members and senior staff and senior members. This is to be compared with the other half of senior members who held a similar view but were of the view that this happens on a little or on a very little scale. The story is the same from the side of the senior and junior staff with the overall picture being that there is a split decision on the issue of interdependence as a factor in inter-group conflict between junior staff and senior staff, junior staff and senior members and senior staff and senior members respectively. According to Schnake (1987), interdependence is a situation where one party cannot complete its work unless the other party does its work. He explains further that task interdependence results in conflict for two main reasons. The first is when only one group is dependent: the independent group may not feel the need to comply with requests. The second situation where task interdependence can result in conflict is when the 
parties have different goals, priorities, or disagree upon the way the tasks should be performed. Thus, when two or more individuals or groups are dependent upon one another for successful job performance, the opportunity for conflict increases. The issue of time pressure as a dimension of inter-group conflict was also investigated. The responses as shown in the table suggest that none of the senior members is associated with the fact that to a very large extent time pressure results in inter-group conflict.

In other words, few of the senior members would want to believe that tine pressure results in inter-group conflict to a large extent. This is to be compared with the majority of senior members who expressed the opinion that indeed time pressure could lead to inter-group conflict but that this is to a little extent or to a very little extent. From the senior members as majority 52 (54.2\%) were of the view that truly time pressure actually results in inter-group conflict but it does so to a little extent or to a very little extent. This is to be compared with $44(45.8 \%)$ of the senior staff who indicated that time pressure results in inter-group conflict to a large or to a very large extent. Turning to the junior staff side, it can be seen that about $77(70 \%)$ of them clearly expressed the view that time pressure to a large or to a very large extent leads to inter-group conflict between junior staff and senior staff, junior staff and senior members and senior staff and senior members respectively. Thus of the 262 respondents investigated as many as 137 (52.3\%) respondents think that time pressure results in inter-group conflict between junior staff and senior staff, junior staff and senior members and senior staff and senior members respectively. The last issue concerning inter-group conflict that was investigated by this study was on the extent to which the issue of collective decision-making results in conflict between the various study groups. Results from the table demonstrate clearly that majority of each study group were of the view that collective decision-making results in conflict between junior staff and senior staff, junior staff and senior members, majority totaling $40(71.5 \%)$ attests to the fact that to a very large extent or to a very large extent the issue of collective decision-making results in inter-group conflict in comparison with those who also held the same view but think that collective decision-making results in inter-group conflict to a little or to a very little extent.

In respect of the senior staff and junior staff majority $56(58.4 \%)$ and $88(80 \%)$ respectively reported that they believe that collective decision-making results in inter-group conflict among the various categories of staff, this is to be compared with the minority of senior staff $40(41.7 \%)$ junior staff $22(20 \%)$ respectively who held the view that collective decision-making results in inter-group conflict among the various categories of staff to a little or to a very little extent. Further examination of the frequencies in Table 9, reveals that, no senior member expressed the view that collective decision-making results in inter-group conflict among the various categories of staff to a large extent. Similarly, no junior staff expressed the view that collective decision-making results in inter-group conflict among the various categories of staff to a little extent. But the general picture is that, majority totaling 160 (61.1\%) support the idea that collective decisionmaking results in inter-group conflict among the various categories of staff. This suggests that even though collective decision-making in itself is not bad, collective decisions may not work in all cases. This confirm Kreitner and Kinicki's (2004) ascertain that the greater the number of people participating in decision making, the greater the potential for conflict. With regard to interviews conducted, poor communication and gossip emerged as a major cause of conflict between junior staff and senior staff. On the factors that promote conflict between junior staff and senior member. Salary disparities and inferiority complex among junior staff were identified as the leading causes. On the side of senior staff and senior members "Pull him down spirit" among senior staff and "lack of proper job description" were mentioned as the key factor that lead to conflict among them.

By way of summary, all the seven issues relating to inter-group conflicts were found to be sources of intergroup conflicts but these are not occurring to the same extent between junior staff and senior staff, junior staff and senior members and senior staff and senior members respectively. However, for each of the issues of conflict investigated, the majority of the respondents clearly indicated that such issues lead to inter-group conflict and occur to a large extent or to a very large extent as compared to those who think that such issues contribute to inter-group conflict to a little or to a very large extent. Additionally, this study has revealed that the issue of limited resources and time pressure were viewed by the majority of senior members and senior staff as resulting in inter-group conflict to a little or to a very little extent. Next, the issue f overlapping tasks and collective decision-making were seen by the majority of the senior members as resulting in inter-group conflict to a little or to a very little extent. Another observation is that here was a split in decision among the 
junior staff on the issue of conflict of interest regarding the extent to which it results in inter-group conflict. Again, there was another split decision regarding the extent to which interdependence results in inter-group conflict. Indeed, this trend of response was observed among the senior members, senior staff and junior staff.

Causes of Conflict among various Schools in the Takoradi Polytechnic: Another dimension of inter-group conflict that the study considered hinges on the various schools in the polytechnic. Table 7 reveals the staff responses on conflicts among various schools as a result of the following causes; limited resources, deficiencies in information flow, conflicting interest, overlapping tasks, interdependence, time pressure, collective decision making.

Table 7: Causes of Conflicts among Various Schools in the Polytechnic

\begin{tabular}{|c|c|c|c|c|c|c|c|c|c|c|c|}
\hline \multirow[t]{3}{*}{ Causes } & \multirow[t]{3}{*}{ Respondents } & \multicolumn{10}{|c|}{ Frequency/Percentage Responses } \\
\hline & & \multicolumn{2}{|c|}{$\begin{array}{l}\text { Very Large } \\
\text { Extent }\end{array}$} & \multicolumn{2}{|c|}{$\begin{array}{l}\text { Large } \\
\text { Extent }\end{array}$} & \multicolumn{2}{|c|}{$\begin{array}{l}\text { Little } \\
\text { Extent }\end{array}$} & \multicolumn{2}{|c|}{$\begin{array}{l}\text { Very Little } \\
\text { Extent }\end{array}$} & \multicolumn{2}{|c|}{ Total } \\
\hline & & $\mathbf{N}$ & $\%$ & $\mathbf{N}$ & $\%$ & $\mathbf{N}$ & $\%$ & $\mathbf{N}$ & $\%$ & $\mathbf{N}$ & $\%$ \\
\hline \multirow[t]{4}{*}{ Limited resources } & SM & 8 & 14.3 & 32 & 57.1 & 16 & 28.6 & 0 & 0 & 56 & 100 \\
\hline & SS & 48 & 50.0 & 40 & 41.7 & 4 & 4.0 & 4 & 4.2 & 96 & 100 \\
\hline & JS & 88 & 80.0 & 0 & 0 & 0 & 0 & 22 & 20.0 & 110 & 100 \\
\hline & Total & 144 & 55.0 & 72 & 27.5 & 20 & 7.6 & 26 & 9.9 & 262 & 100 \\
\hline Deficiencies & SM & 12 & 21.4 & 28 & 50.0 & 8 & 14.3 & 8 & 14.3 & 56 & 100 \\
\hline \multirow[t]{3}{*}{ Information flow } & SS & 24 & 25.0 & 56 & 58.3 & 12 & 12.5 & 4 & 4.2 & 96 & 100 \\
\hline & JS & 11 & 10.0 & 77 & 70.0 & 11 & 10.0 & 11 & 10.0 & 110 & 100 \\
\hline & Total & 27 & 17.9 & 161 & 61.5 & 31 & 11.8 & 23 & 8.8 & 262 & 100 \\
\hline \multirow[t]{4}{*}{ Conflict interest } & SM & 20 & 35.7 & 12 & 21.4 & 4 & 7.1 & 20 & 35.7 & 56 & 100 \\
\hline & SS & 20 & 20.8 & 44 & 45.8 & 28 & 29.2 & 4 & 4.2 & 96 & 100 \\
\hline & JS & 22 & 20.0 & 44 & 40.0 & 33 & 30.0 & 11 & 10.0 & 110 & 100 \\
\hline & Total & 62 & 23.7 & 100 & 38.2 & 65 & 24.8 & 35 & 13.4 & 262 & 100 \\
\hline Overlanning & SM & 12 & 214 & 24 & 429 & 16 & 286 & 4 & 71 & 56 & 100 \\
\hline \multirow[t]{4}{*}{ Tasks } & SS & 24 & 25.0 & 44 & 45.8 & 20 & 20.8 & 8 & 8.3 & 96 & 100 \\
\hline & JS & 22 & 20.0 & 55 & 50.0 & 11 & 10.0 & 22 & 20.0 & 110 & 100 \\
\hline & Total & 58 & 22.10 & 123 & 46.9 & 47 & 17.9 & 34 & 13.0 & 262 & 100 \\
\hline & & & & & & & & & & & 100 \\
\hline \multirow{4}{*}{ Interdependence } & SIM & 8 & 14.3 & 10 & 20.0 & 8 & 14.3 & 24 & 42.9 & 56 & 100 \\
\hline & SS & 12 & 12.5 & 24 & 25.5 & 40 & 41.7 & 20 & 20.8 & 96 & 100 \\
\hline & JS & 11 & 10.0 & 22 & 20.0 & 0 & 0 & 77 & 70.0 & 110 & 100 \\
\hline & Total & 31 & 11.8 & 62 & 23.7 & 48 & 18.3 & 121 & 46.2 & 262 & 100 \\
\hline \multirow{5}{*}{ Time Pressure } & SM & 8 & 14.3 & 24 & 42.9 & 8 & 14.3 & 16 & 28.6 & 56 & 100 \\
\hline & SS & 36 & 37.5 & 28 & 29.2 & 28 & 29.2 & 4 & 4.2 & 96 & 100 \\
\hline & JS & 77 & 70.0 & 11 & 10.0 & 0 & 0 & 22 & 20.0 & 110 & 100 \\
\hline & Total & 121 & 46.2 & 63 & 24.0 & 36 & 13.7 & 42 & 16.0 & 262 & 100 \\
\hline & & & & & & & & & & & 100 \\
\hline Collective & SM & 12 & 21.4 & 20 & 35.7 & 16 & 28.6 & 8 & 14.3 & 56 & 100 \\
\hline \multirow[t]{3}{*}{ Decision Making } & SS & 24 & 25.0 & 40 & 41.7 & 32 & 33.3 & 0 & 0 & 96 & 100 \\
\hline & JS & 22 & 20.0 & 55 & 50.0 & 0 & 0 & 33 & 30.0 & 110 & 100 \\
\hline & Total & 58 & 22.1 & 115 & 43.9 & 48 & 18.3 & 41 & 15.60 & 262 & 100 \\
\hline
\end{tabular}

Key: $\quad$ SM - Senior Members

SS - Senior Staff

JS - Junior Staff

Results from table 7 demonstrate clearly that the majority of the senior members totaling 32 (57.1\%) attest to the fact that to a large extent limited resource is an issue that leads to conflict among various schools at the polytechnic. None of the senior members agreed to the fact that limited resources to a very little extent contribute to conflict among various schools at the polytechnic. In respect of the senior staff 48 (50.0\%), 
attest to the fact that to a very large extent limited resources contribute to conflict among various schools at the polytechnic with only $8(8.4 \%)$, agreeing to the fact that to a very little extent or to a little extent limited resources contributes to conflict among various schools at the polytechnic. Turning to the junior staff side, as much as $88(80 \%)$, attest to the fact that to a very large extent limited resource is an issue that leads to conflict among various schools at the polytechnic with only $22(20 \%)$, agreeing to the fact that it does so to a very little extent. None of them supported the idea that limited resources contributes to conflicts among various schools at the polytechnic to a large extent or little extent. The study has revealed that the majority of the staff indicated that to a very large extent or to a large extent the suggestion that conflicts among various schools is as a result of limited resources is one of the sources of conflict. In particular, most junior staff 88 $(80 \%)$ attested to this issue in comparison with the senior members and senior staff. In all, 144 (55\%) of the respondents reported that they were of the opinion that to a very large extent or to a large extent, conflicts among various schools is attributable to limited resources in the system. This is an indication of the need to ensure that adequate resources are to be provided and distributed fairly among staff of the various schools. According to Stoner (1978), if every unit in an institution has access to unlimited resources, the problem of how to share it would hardly arise. Nelson and Quick (2000) share the same view that limited resources are potential for conflict in institutions especially where these resources become scarce and need to be shared. Next, the extent to which deficiencies in information flow results in conflict among the various schools was investigated.

Table 7, reveals the staff responses on this issue. Critical study of the table shows that half of the number of the senior members investigated expressed the opinion that to large extent deficiencies in information flow contributes to conflict among the various schools with only $16(28.6 \%)$ agreeing to the fact that to a very little extent or to a little extent deficiencies in information flow lead to conflict among the various schools in the polytechnic. The interview data also confirmed the inefficiencies in information flow. This is exemplified by a comment by one senior member. Even though the polytechnic is a tertiary institution and has structures for ensuring that staff are informed about events that affects them, it appears these structures do not function. You'll be there and you'll hear about an event going on at times from people outside the polytechnic when staff has not been given prior information. To be honest such a situation creates tension and makes some of us feel not belonging' (An academic head).The story is not different on the side of the senior staff and the junior staff. For instances, as many as $77(70 \%)$ of the junior staff expressed the same view. Indeed, about 188 (79.4\%) of the staff expressed this opinion. This suggests that information flow is a very important ingredient if cooperation and co-ordination of activities among the various schools are to be effective and efficient. Schnake (1987) writes that absence of information flow in institutions leads to suspicion; misconception and distrust which he stressed are typical promoters of conflict. In response to the issue of conflicting interest as a cause of conflict among the various schools, the story is not different from the two previous responses given. Data in the table demonstrate that most respondents also view conflicting of interest resulting in conflicts among the various schools. For instance, in relative terms, majority 66 (66.6\%) of the senior staff responded by saying that to a very large extent or to a large extent conflicting interest is a cause of conflicts among the various schools.

In all however, about $162(62 \%)$, of respondents expressed this view. The polytechnic is made up of working groups such as department, schools etc. It could be that these groups experience what is termed in management as 'we feeling' which binds group members together. According to Kreitner and Kinicki (2004), in-group thinking in institutions guarantee conflict since the desire to get along pushes aside critical thinking. The next cause of conflict considered under the various schools was on overlapping task. Responses given depict that the majority of the respondents totaling 181 (69\%) of the respondents reported that overlapping task to a very large extent or to a large extent leads to conflict among the various schools. A case in point from the table is that $68(66.6 \%)$ of the senior staff has viewed this factor as a source of conflict. This finding support the explanation of Kreitner (1998), that the term role ambiguity as overlapping jurisdiction leads to unclear job boundaries which often create competition for resources and control. For the majority of the respondents to believe that overlapping tasks contribute to conflict among the schools suggest the need to ensure that tasks sharing should be a concerted effort and not based on the individual schools. With regard to the issue of interdependence, the responses took a different dimension as depicted in the table. As many as $169(64.5 \%)$ of the respondents with most of them being junior staff $77(70 \%)$ think that conflict among the various schools as a result of interdependence can be described as to a very little or little extent. This 
suggests how useful respondents perceive the issue of interdependence in minimizing conflict among the various schools. It could also be that the schools are autonomous; hence they operate independently creating little room for conflict. Another issue that this study looked at as a possible source of conflict among the various schools was time pressure. Results of the findings on this issue suggest that most respondent 184 (70.2\%) perceived time pressure to be accuse of conflict with the majority of the respondents being the junior staff $88(80 \%)$ who perceived time pressure as resulting in conflict among the various schools.

This is an indication of the need for effective and efficient time management practices to be considered if time pressure is to be reduced. Also, for the majority of respondents to reason that time pressure results in conflict among the schools suggests the need for the authorities to regularly remind staff on the importance of time management. The last issue on the causes of conflict among various schools had to do with collective decision-making. The story here is that majority of the respondents think that collective decision-making to a very large extent or to a large extent is also responsible for conflicts among the various schools. Indeed, most of the junior staff $77(70 \%)$ in comparison with the senior members and the senior staff are aligned to the view that collective decision-making to a very large extent or to a large extent is also responsible for conflicts among the various schools. This suggests that even though collective decision making in itself is not bad, collective decisions may not work in all cases. This confirms Kreitner and Kinicki's (2004), assertion that, the greater the number of people participating in decision making, the greater the potential for conflict. The result from interview sessions reveal that improper allocation of resources especially money, discrimination and favoritism by management were the causes of departmental and school conflict. The interview sessions sought to find out the extent to which conflict occur among various groups of staff, departments and schools. The result indicated that with the exception of conflict between junior staff and senior staff where the extent of it is to some extent. The extent to which conflict occur among junior staff and senior members, senior staff and senior members, various departments and schools can be said to occur to a little or very little extent. This can be a sign of peaceful co-existence and good development, yet, conflict by nature starts from petty conflict to a very serious one. However, the extent of occurrence plays a very importance role in the determination of what strategies to adopt in managing a particular kind of conflict. Another area that the interview gathered information on was the extent to which conflicts are encountered with regard to motivation and incentives to staff issues such as allowances, staff development, staff accommodation, annual leave and staff promotion were ascertained.

The result revealed that conflict is encountered with regard to staff allowances and staff accommodation to a very large extent while conflict is encountered with regard to staff development, annual leave and staff promoting to some extent, very little extent and little extent respectively. Commonly held view among the senior members who were interviewed may, perhaps, is summed up in the words of one of them as follows: As for this polytechnic, rules governing the allocation of accommodation are not observed. You can be in the polytechnic for fifteen years but some comes in for just three years and before you are aware, he has been allocated a bungalow. This practice brings about conflict (An Assistant Registrar).The view of senior members on the causes of conflict in general in the interviewed was no different from the causes enumerated above. Results from the interview indicated that "fighting for positions and favors"' and "non-payment or delay in allowances were the highest causes of conflict in the institution. The other causes mentioned included, role conflict, problems with job placement, lack of motivation, lack of cooperation, lack of coordination, poor communication structure among staff, cultural and religious differences and use of lecture halls. It can be realized that most of the causes indicate by the selected senior members are not different from what were gathered under the questionnaire.

\section{Conclusion}

Based on the findings, a number of conclusions can be drawn. Conflict at all levels exists among staff of Takoradi Polytechnic. These are intra-personal, inter-personal and inter-group. The various causes of these levels of conflict have been established. As indicated earlier, conflict is inevitable in all human institution; successful organizations encourage mild forms of conflict without having it escalate into an emotional battle between employees or corporate divisions. The secret is to keep conflict task related and to prevent it from escalating to a social-emotional state. When conflict is task related, the parties view the conflict experience as something separate from them. This conflict is potentially healthy and valuable because it makes people 
rethink their perspectives of reality. As long as the conflict remains focused on issues, new ideas may emerge and the conflict remains controlled. It is therefore paramount for individual as well as management to apply the most effective conflict management style to minimize the dysfunctional aspect of conflict and maximize the functional aspect for the growth and development of both parties involved and the organization as a whole.

Recommendations for Practice: Based on the findings and conclusions drawn from the study, the following recommendations are made: Management of Takoradi Polytechnic should educate the staff that due to differences in cultural orientations, educational background, social status, age and other such considerations, there are bound to be misunderstandings and disagreements at the work place. Such situations should be taken in good faith and deal with, for peaceful co-existence and healthy organizational climate. Management of Takoradi Polytechnic should as a matter of urgency search for other avenues to generate funds to beef up infrastructural and logistical resources of the polytechnic. Part-time lectures, 'sandwich' programs, renting of facilities during recess, fairs and exhibitions could be considered. These will help address some of the challenges that lead to intra-personal and group conflicts among staff. The human resource department should organize seminars periodically on topics that will increase the confidence level of the staff of Takoradi Polytechnic especially the junior staff. This will help them to believe in themselves and inspire them to learn to attain higher positions in future. The above recommendations when adopted could in no small way help Takoradi Polytechnic achieve the best in terms of staff-related conflict management practices.

\section{References}

Bagshaw, M. (1998). Conflict management and mediation: Key leadership skills for the millennium. Industrial and commercial training, 30 (6), 206-208.

Barker, J., Tjosuold, D. \& Andrews, R. J. (1988). Conflict approaches of effective project managers: A filed study in a matrix organization. Journal of Management Studies, 2, 167-176.

Certo, S. C. (2000). Supervision: Concepts and skill building. (3 ${ }^{\text {rd }}$ Ed.). Boston: McGraw Hill Inc.

Dahrendorf, R. (1989). Class and class conflict in industrial society. Stanford, CA: Stanford University Press.

Esquival, M. A. \& Kleiner, B. H. (1997). The importance of conflict in work team effectiveness. Team Performance Management, 3(2), 89-96.

French, R. M. (2000). The community a comparative perspective (3 ${ }^{\text {rd }}$ Ed.). Illinois: F.E. Peacock Publishers Inc.

Hellriegel, D., Solocum, J. W. \& Woodman, R. W. (1998). Organizational behavior. Cincinnati, OH: Southwestern College Publishing.

Kinard, J. (1988). Management. Massachusetts: D.C. Health and Company.

Kreitner, R. \& Kinicki, A. (2004). Organizational behavior (6 ${ }^{\text {th }}$ Ed.). New York: McGraw-Hill Irwin.

Kreitner, R. (1998). Management. California: Houghton Mifflin Company.

Likert, R. \& Likert, J. (1976). New ways of managing conflict. New York: McGraw-Hill.

McShane, L. S. \& Glinow, M. A. U. (2000). Organizational Behavior, New York: McGraw-Hill Companies.

Mullins, J. L. (2005). Management and Organizational Behavior. New York: Prentice Hall.

Nelson, L. D. \& Quick J. C. (2000). Organizational Behavior: Foundations, realities and Challenges (3 ${ }^{\text {rd }}$ Ed.). New Jersey: South Western College Publishing.

Oppong, M. K. (1999). Conflict management behaviors' of headmasters in senior secondary schools in Kwehu. Unpublished master thesis, University of Cape Coast, Cape Coast.

Pondy, L. (1969). Varieties of Organizational Conflict Administrative. Science Quarterly, 14, 499-505.

Rao, M. G., Rao, U. S. P. \& Narayana, P. S. (1987). Organizational Behavior: Text and cases. New Delhi: Konaark Publishers.

Sawyer, A. (1997). Dynamics of Conflict Management in Liberia. Accra: An Institute of Economic Affairs Publication.

Schnake, M. E. (1987). Principles of supervision. Dubugne, Iowa: W.C. Brown Publisher.

Stoner, J. A. (1978). Management. New Jersey: Prentice-Hall Inc.

Wright, P. M. \& Noe, R. A. (1996). Management of organizations. Boston: McGraw-Hill. 